\title{
RAPID SEPARATION AND DETERMINATION OF RIZATRIPTAN N-OXIDE IMPURITY IN RIZATRIPTAN BENZOATE IN A BULK DRUG SUBSTANCE BY REVERSE PHASE LIQUID CHROMATOGRAPHY
}

\author{
APPASAHEB B LAWANDE* \\ Department of Chemistry, Shri Jagdish Prasad Jhabarmal Tibrewala University, Vidyanagari, Jhunjhunu - 333 001, Rajasthan, India. \\ Email: ab.lawande@rediffmail.com
}

Received: 18 October 2016; Revised and Accepted: 22 October 2016

\begin{abstract}
Objective: The objective is described to develop and validate a simple, reliable, precise, and specific analytical method for rapid separation and determination of $\mathrm{N}$-oxide impurity in rizatriptan Benzoate active pharmaceutical ingredient bulk drug substances by reverse phase liquid chromatography as per the International Conference on Harmonization (ICH) guidelines.

Methods: The methodology utilized as reverse phase liquid chromatography with gradient composition. The mobile phase proportion was compromised mobile A containing $0.25 \mathrm{~mm}$ potassium dihydrogen phosphate buffer $\mathrm{pH} 2.0$ and methanol $(95: 5 \mathrm{v} / \mathrm{v})$ and mobile B containing Acetonitrile. ODS 3V, $250 \times 4.6 \mathrm{~mm}, 5 \mu \mathrm{m}$. column. The flow rate is $1.0 \mathrm{ml} /$ minute using an LC system detector at wavelength $280 \mathrm{~nm}$, and the column oven temperature is $40^{\circ} \mathrm{C}$. The chromatographic separation performed in reverse phase by the gradient composer over run time was 35 minute. The resolution between $\mathrm{N}$-oxide and rizatriptan was recorded on the chromatogram was more than six. The developed analytical method was validated according to the ICH guidelines.
\end{abstract}

Results: Linearity was found in rizatriptan N-oxide over the concentration range of 450-11000 ng/ml, with the linear regression (Correlation coefficient $\mathrm{R}=0.999$ ) and proved to be robust. Limit of detection and limit of quantification of the rizatriptan $\mathrm{N}$-oxide was found 150 and $450 \mathrm{ng} / \mathrm{ml}$. The retention time of rizatriptan and rizatriptan $\mathrm{N}$-oxide was recorded 22.6 and 24.7 minutes, respectively. The percentage recovery of $\mathrm{N}$-oxide has been ranged from 96.0 to 102.0 in the bulk drug material sample. The proposed analytical method has been found suitable, precise, reliable, and accurate for the separation and quantitative determination.

Conclusion: A specific, simple, accurate, reliable, and rapid reproducible analytical method has been developed and validated for reverse phase highperformance liquid chromatography to determine N-Oxide impurity in rizatriptan benzoate from bulk drugs material as per ICH guideline.

Keywords: Rizatriptan benzoate, N-oxide impurity, High performance liquid chromatography, Reverse phase, ODS column and validation.

(C) 2017 The Authors. Published by Innovare Academic Sciences Pvt Ltd. This is an open access article under the CC BY license (http://creativecommons. org/licenses/by/4. 0/) DOI: http://dx.doi.org/10.22159/ajpcr.2017.v10i2.15751

The method validated at different parameters, i.e., specificity and system suitability, precision, limit of detection, limit of quantitation, robustness, linearity and range and also mobile phase stability.

\section{INTRODUCTION}

Rizatriptan benzoate, (N, N-dimethyl-2-[5-(1, 2, 4-triazole-1-ylmethyl)$1 \mathrm{H}$-indol-3-yl]ethanamine monobenzoate). Rizatriptan belongs to the class of triptans [1]. Rizatriptan benzoate is used to relieve the pain, headache, and treat to migraines [2]. It helps to return normal routine promptly and decreases of other pain medications [3]. Its molecular formula is $\mathrm{C}_{22} \mathrm{H}_{25} \mathrm{~N}_{5} \mathrm{O}_{2}$ and molecular weight is $391.5 \mathrm{~g} / \mathrm{mole}$. Rizatriptan benzoate is active pharmaceutical ingredients used in manufacturing of finished dosage form of tablets for oral use. The chemical structures show rizatriptan benzoate in Fig. 1. The molecular formula of rizatriptan $\mathrm{N}$-oxide impurity is $\mathrm{C}_{15} \mathrm{H}_{19} \mathrm{~N}_{5} \mathrm{O}$ and molecular weight is $285.35 \mathrm{~g} / \mathrm{mole}$ and chemical structures show of Fig. 2.

"Rizatriptan degradation product" refers to a compound resulting from a chemical modification of rizatriptan. The modification, for example, can be the result of a thermally or photochemically induced reaction. Such reactions include, without limitation, oxidation (e.g., N-oxide formation), elimination (e.g., $\mathrm{E}_{1}$ and $\mathrm{E}_{2}$ reaction pathways), and dimerization [4]. The more content of n-oxide affected to the patient more common is blurred vision, unusual tiredness or weakness, etc. Hence, it can be required to control at before commencing of manufacturing of finished dosage form.
The number of methods was reported to the determination of impurities on reverse phase high-performance liquid chromatography (HPLC), but there were no methods available for determination of $\mathrm{N}$-oxide content in rizatriptan benzoate. This report describes a gradient program, reverse phase liquid chromatography method for the precise and rapid. The method was validated for quantitative determination of $\mathrm{N}$-oxide in rizatriptan benzoate in bulk drug substances. Referred other products analytical method for support of method validation [5-8].

\section{MATERIALS AND METHODS}

\section{Material and standards}

Rizatriptan benzoate, N-oxide impurity kindly gifted by Lavender Laboratories Private Limited, Kurkumbh, Pune, Maharashtra, India.

Chemicals and reagents

Potassium dihydrogen phosphate A.R. grade, which was purchased from Rankem, Orthophosphoric acid A.R. grade, purchased from Mark.

Methanol used as gradient grade purchased from Thermo Fisher Scientific India Pvt. Ltd. Acetonitrile used as gradient grade purchased from Thermo Fisher Scientific India Pvt. Ltd. Purified water, HPLC and spectroscopy grade purchased from Finar limited.

\section{Instrument specification}

A HPLC system consists of Shimadzu 2010 series with UV detector and inbuilt autoinjector was utilized for method development and 


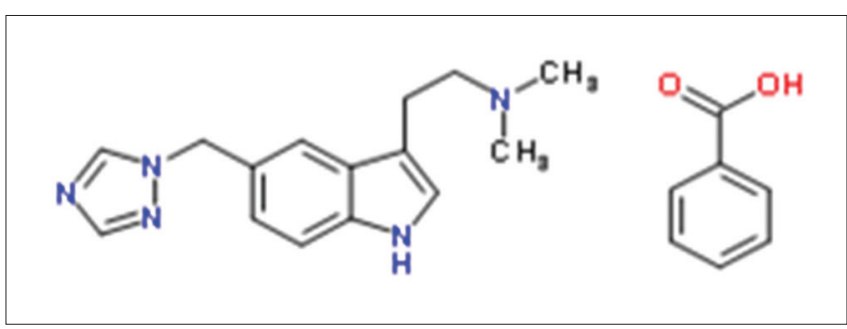

Fig. 1: Chemical structure: Rizatriptan benzoate

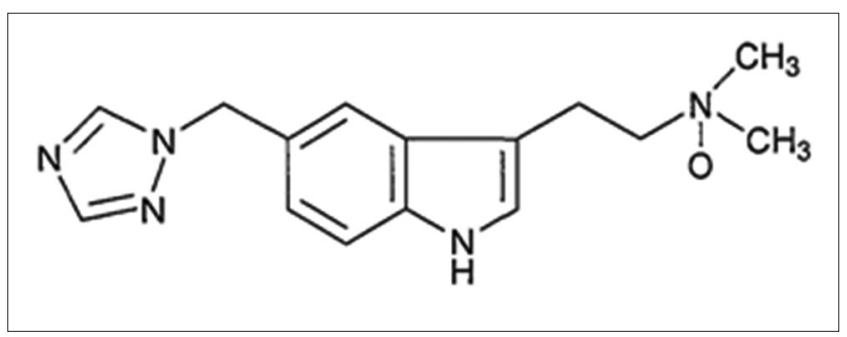

Fig. 2: N,N-dimethyl-5-(1 H-1 ,2,4-triazol-1-yl-methyl)-1 $\mathrm{H}$-indole-3- ethanamine $\mathrm{N}$-oxide

validation. The chromatography analysis was performed using ODS 3V, $250 \times 4.6 \mathrm{~mm}$ internal diameter and $5 \mu \mathrm{m}$ particle size of the column. The used software was LC solution software for data acquisition and system suitability calculation. Calibrated analytical Corporation, Japan. Labindia $\mathrm{pH}$ meter was used for $\mathrm{pH}$ adjustment for buffer preparation of mobile phase. Analytical balance used for weighing of standard and samples, electronic balance type 2000 Shimadzu.

\section{Chromatographic conditions}

Buffer: $0.25 \mathrm{~mm}$ potassium dihydrogen phosphate buffer adjusted pH 2.0 with dilute orthophosphoric acid.

Mobile phase (v/v):

- Mobile phase A: Buffer: Methanol (95: $5 \mathrm{v} / \mathrm{v}$ )

- Mobile phase B: Acetonitrile

- Column: ODS 3V, $250 \mathrm{~mm} \times 4.6 \mathrm{~mm}, 5$ micron.

- Flow rate: $1.0 \mathrm{ml} /$ minute.

- Column oven temperature: $40^{\circ} \mathrm{C}$.

- UV detection wavelength: $280 \mathrm{~nm}$.

- The injection volume: $20 \mu \mathrm{l}$.

- Mode of analysis: Gradient

- Run time: 35 minute.

- Diluent: Mobile phase B.

\begin{tabular}{lll}
\hline $\begin{array}{l}\text { Gradient program } \\
\text { Program time }\end{array}$ & $\begin{array}{l}\text { Mobile phase A } \\
\text { (v/v\%) }\end{array}$ & $\begin{array}{l}\text { Mobile phase B } \\
\text { (v/vo) }\end{array}$ \\
\hline 0.01 & 95 & 5 \\
15 & 95 & 5 \\
25 & 60 & 40 \\
26 & 95 & 5 \\
35 & 95 & 5 \\
\hline
\end{tabular}

The data were analyzed in the LC solution software. Before analysis, Mobile Phase A and Mobile Phase B was filtered through a $0.2 \mathrm{~mm}$ membrane filter and digassed to remove dissolved gases if any.

\section{METHOD DEVELOPMENT}

\section{Rizatriptan benzoate standard solution}

Accurately weighed and transferred $50 \mathrm{mg}$ of rizatriptan Benzoate working standard into $10 \mathrm{ml}$ cleaned and dried volumetric flask, added $7 \mathrm{ml}$ diluent, sonicated to dissolve and made up to the final volume with diluent to prepare a $5000 \mu \mathrm{g} / \mathrm{ml}$ solution (Stock solution A).
Table 1: Validation results of the developed normal phase method

\begin{tabular}{cll}
\hline S.N & Validation parameter & Results \\
\hline A & Repeatability (n=6, \%RSD) & \\
1 & $\quad$ Retention time of rizatriptan & 0.6 \\
2 & Retention time of rizatriptan N-oxide & 0.5 \\
3 & Peak area of rizatriptan & 1.9 \\
4 & Peak area of rizatriptan N-oxide impurity & 1.8 \\
B & Intermediate precision (n=18, \%RSD) & \\
1 & Retention time of rizatriptan & 0.6 \\
2 & Retention time of rizatriptan N-oxide & 0.5 \\
3 & Peak area of rizatriptan & 1.7 \\
4 & Peak area of rizatriptan N-oxide & 1.6 \\
C & LOD-LOQ (rizatriptan N-oxide impurity) & 150 \\
1 & Limit of detection (ng/ml) & 450 \\
2 & Limit of quantification (ng/ml) & 1.9 \\
3 & Precision at LOQ (\% RSD) & \\
D & Linearity (rizatriptan N-oxide impurity) & $450-11000$ \\
1 & Calibration range (ng/ml) & 6 \\
2 & Calibration points & 0.999 \\
3 & Correlation coefficient &
\end{tabular}

Rizatriptan N-oxide impurity solution

Accurately weighed and transferred $3.75 \mathrm{mg}$ of rizatriptan N-oxide impurity standard into $50 \mathrm{ml}$ cleaned and dried volumetric flask, added $35 \mathrm{ml}$ diluent and dissolved, mixed and made up to the final volume with diluent to prepare a $75 \mu \mathrm{g} / \mathrm{ml}$ solution (Stock solution B). Further transferred $5 \mathrm{ml}$ of this solution into 50 volumetric flask, added $35 \mathrm{ml}$ diluent, mixed and made up to the final volume with diluent to prepare $7.5 \mu \mathrm{g} / \mathrm{ml}$ impurity standard solution w.r.t. Rizatriptan Benzoate standard solution.

\section{Resolution solution}

Transferred $1 \mathrm{ml}$ of stock solution A and $1 \mathrm{ml}$ of stock solution B into $10 \mathrm{ml}$ cleaned and dried volumetric flask, added $7 \mathrm{ml}$ diluent, mixed and made up to the final volume with diluent.

\section{VALIDATION OF DEVELOPED METHOD}

\section{Selectivity and specificity}

The ability of a method to well separate and accurately measure specifically of selectively the eluted peaks in the presence of components that may be expected to be present in the sample. The blank, i.e., diluent, impurity, standard, resolution, solution, and test preparations were analyzed as per the method to identify interference of blank and degradation with rizatriptan $\mathrm{N}$-oxide and rizatriptan peaks. No interference observed corresponding to the analyte peak of a sample solution (Figs. 3-5).

\section{Specificity and system suitability}

System suitability tests are an integral part of HPLC methods and are used to verify that the accuracy and precision of the system are appropriate for the analysis to be performed. Parameters such as tailing factor, resolution, and repeatability, i.e., percentage relative standard deviation (RSD) of retention time and area for six repetitions are determined. The parameters to be measured and their recommended limits obtained from the system suitability sample from the analysis are presented in Table 1.

\section{Method reproducibility}

Developed method was determined by has been reproduced and measuring repeatability by instrument precision and method precision. The intermediate precision was performed on different days for retention times and peak areas of rizatriptan $\mathrm{N}$-oxide.

The instrument precision determined on six replicate injections of rizatriptan $\mathrm{N}$-oxide. Method repeatability determined on six sample injections of a $7.5 \mu \mathrm{g} / \mathrm{ml}$ concentration solution containing $0.15 \%$ with respect to the concentration of sample solution. Intermediate precision was also determined on over a period of the day by carrying successive six replicate injections per day. 


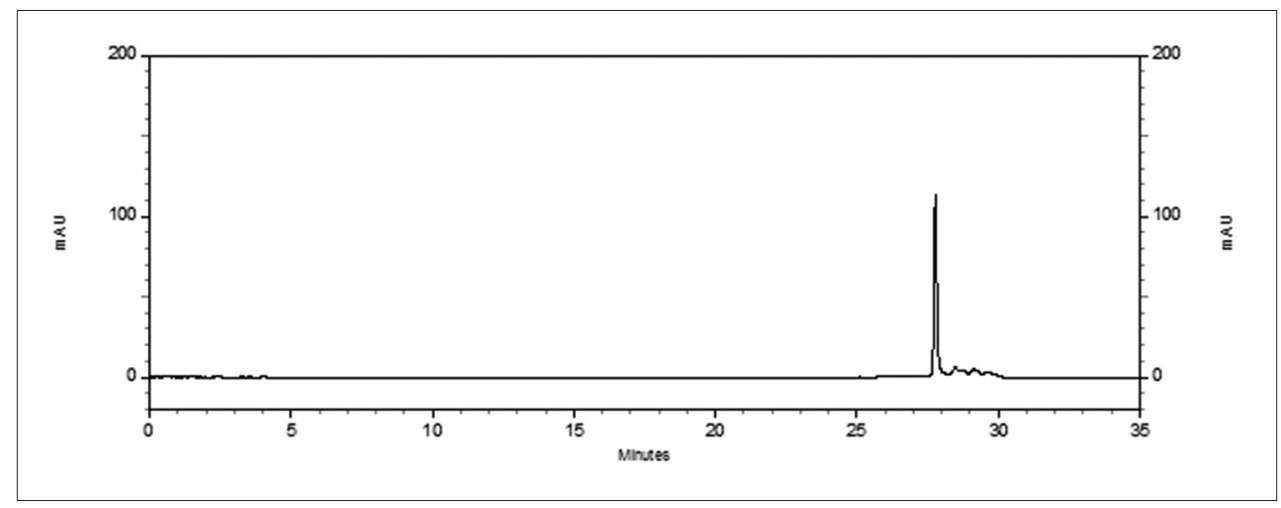

Fig. 3: Typical chromatogram of blank solution

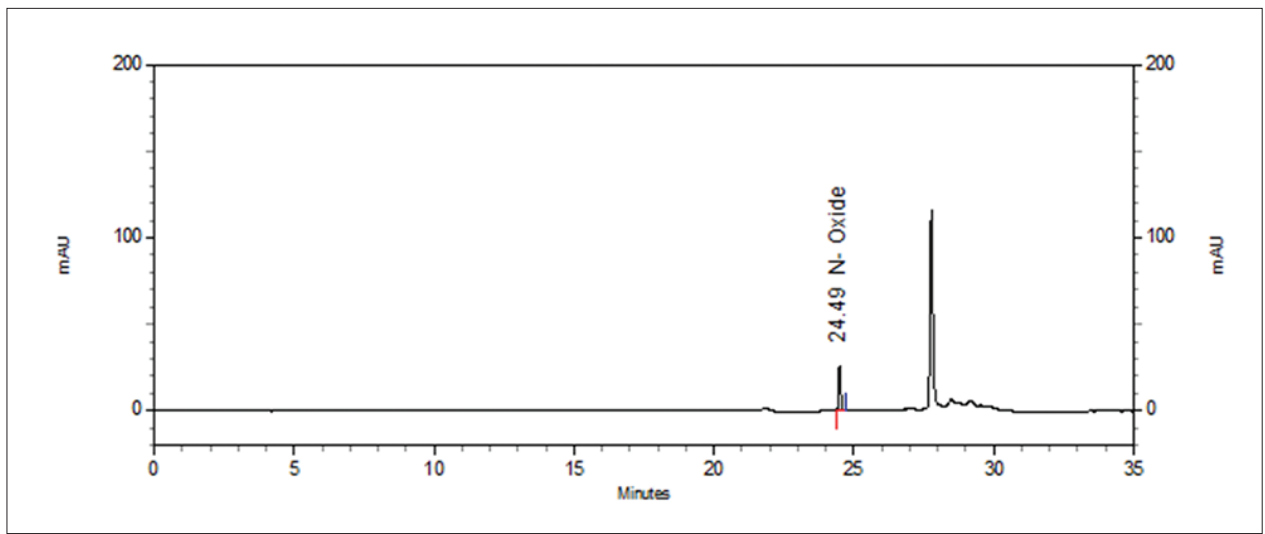

Fig. 4: Typical chromatogram of Id solution of rizatriptan $\mathrm{N}$-oxide

Limit of detection (LOD) and limit of quantification (LOQ) of rizatriptan $\mathrm{N}$-oxide

The LOD, defined as the lowest concentration of analyte that can be accepted at the detection level on above the baseline signal and not required to quantify, the signal was estimated above the baseline as three times the signal to noise ratio.

$\mathrm{LOD}=3.3 \sigma / \mathrm{S}$

The LOQ, defined as the lowest concentration of analyte that can be quantified, reproducible with suitable precision and accuracy, the signal was estimated as ten times the signal to noise ratio.

$\mathrm{LOQ}=10 \sigma / \mathrm{S}$

The LOD and LOQ was achieved by injecting a series of dilute solutions of rizatriptan $\mathrm{N}$-oxide.

The developed method was precise, reliable for determination of rizatriptan $\mathrm{N}$-oxide impurity at the LOQ level was checked by testing with six test solutions of rizatriptan benzoate which was prepared at the LOQ level and percentage RSD calculated for area response.

\section{Linearity and range of R-isomer}

Linearity of detector response was assessed by on six calibration of sample solutions preparation of rizatriptan $\mathrm{N}$-oxide covering range from $450 \mathrm{ng} / \mathrm{ml} \mathrm{(LOQ)} \mathrm{to} 11000 \mathrm{ng} / \mathrm{ml}(450 \mathrm{ng} / \mathrm{ml}, 3750 \mathrm{ng} / \mathrm{ml}$, $5500 \mathrm{ng} / \mathrm{ml}, 7500 \mathrm{ng} / \mathrm{ml}, 9000 \mathrm{ng} / \mathrm{ml}$, and $11000 \mathrm{ng} / \mathrm{ml}$ ), solution was prepared in diluent.

The obtained regression curve was by plotting peak area response against concentration of a solution using the least squares method. Linearity was performed on 3 consecutive days of same concentration range from the same stock solution. The RSD in percentage of the slope and Y-intercept of the calibration curve was calculated.

\section{Accuracy/recovery}

The sample of rizatriptan benzoate was gifted by Lavender Laboratories Private Limited showed the presence of $\mathrm{N}$-oxide impurity is not detected. Recovery experiments and standard addition were conducted to determine the accuracy of this method for the quantification of rizatriptan $\mathrm{N}$-oxide impurity in rizatriptan benzoate bulk drug samples.

The study was carried out in triplicate at $0.05 \%, 0.15 \%$, and $0.25 \%$ of targeted analyte concentration of rizatriptan benzoate. The calculated recovery of the rizatriptan $\mathrm{N}$-oxide was obtained by calibration curve from the slope and Y-intercept.

\section{Robustness}

The method robustness of an ability of the method to remain unaffected by small changes in method parameters, i.e., column oven temperature, flow rate, composition of the mobile phase. To determine the method robustness by experimental conditions was purposely altered and checked chromatographic resolution between rizatriptan and rizatriptan $\mathrm{N}$-oxide impurity were evaluated.

The flow rate of the mobile phase was $1.0 \mathrm{ml} /$ minutes. To study the impact of flow rate on the resolution of rizatriptan and rizatriptan $\mathrm{N}$-oxide impurity, it was changed from $0.8 \mathrm{ml} /$ minute to $1.2 \mathrm{ml} /$ minute by $0.2 \mathrm{ml} /$ minute. The effect of column oven temperature on resolution was changed at $38^{\circ} \mathrm{C}$ and $42^{\circ} \mathrm{C}$ instead of $40^{\circ} \mathrm{C}$. While the mobile phase components and flow rate were held constant as stated. The effect of change in $\mathrm{pH}$ of buffer solution on resolution was studied by varying from -0.1 to +0.1 and other components of mobile phase were held constant as stated. 


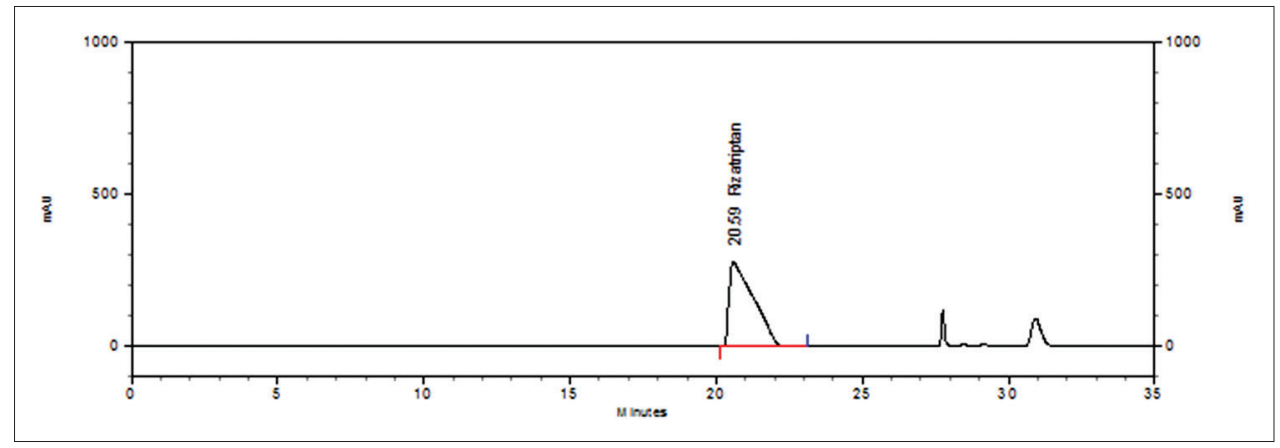

Fig. 5: Typical chromatogram of Id solution of rizatriptan

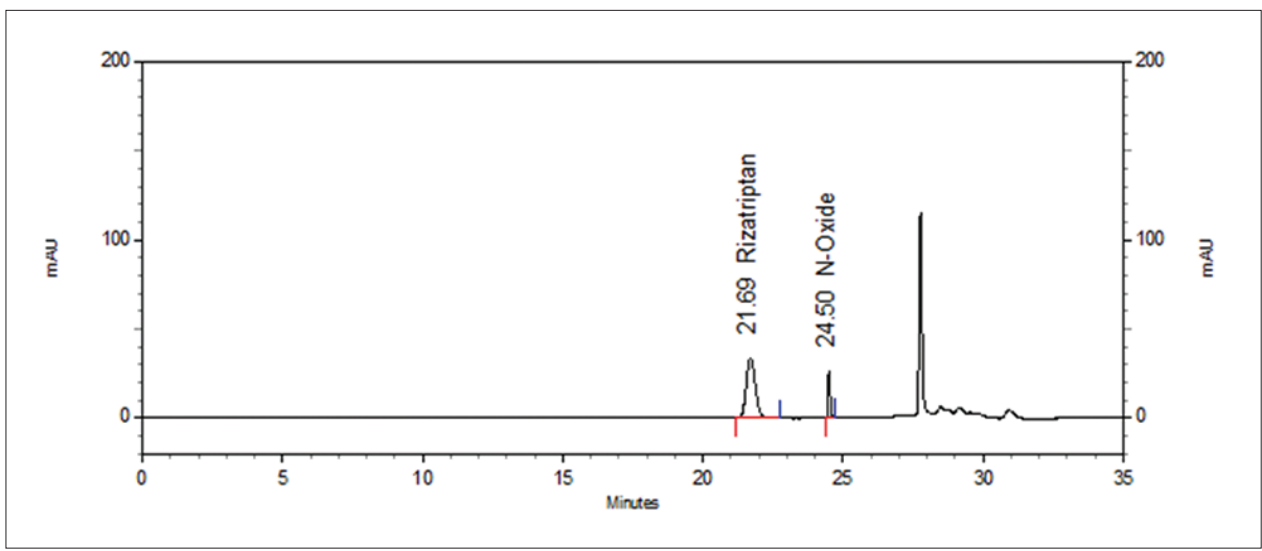

Fig. 6: Typical chromatogram of resolution solution of rizatriptan and N-oxide

\section{Mobile phase stability}

The stability of the mobile phase was carried out by evaluating the content of rizatriptan $\mathrm{N}$-oxide impurity in sample solutions. Freshly prepared samples were injected at every $6 \mathrm{hrs}$ time interval for $48 \mathrm{hrs}$. Same mobile phase was used for both of the experiment during the study period.

\section{RESULTS AND DISCUSSION}

\section{A method development}

The aim of the work is a separation and determination of rizatriptan $\mathrm{N}$-oxide impurity from rizatriptan benzoate using reverse phase HPLC. The $0.0075 \mathrm{mg} / \mathrm{ml}$ solution concentration of prepared of rizatriptan benzoate $\mathrm{N}$-oxide impurity in diluent. Which was used while method development. To develop a rugged, precise, accurate, and suitable LC method for the separation of rizatriptan $\mathrm{N}$-oxide impurity from rizatriptan benzoate. The different mobile phases and stationary phases were employed while performing the experiment. In an experiment has been attempted to separate the rizatriptan $\mathrm{N}$-oxide impurity from rizatriptan benzoate. Various experiments were conducted, to select the best stationary and mobile phases that would give suitable resolution and selectivity for the separation of $\mathrm{N}$-oxide impurity. There is an indication of separation on ODS column using a gradient mode for mobile phase A and mobile phase B containing composition of buffer: Methanol (95: $5 \mathrm{v} / \mathrm{v}$ ) and acetonitrile, respectively. The chromatographic system equipped with detector wavelength $280 \mathrm{~nm}$ and separation was achieved on a ODS, 3V, $(250 \times 4.6 \mathrm{~mm}, 5$ micron $)$ column.

The flow rate of the mobile phase was $1.0 \mathrm{ml} /$ minute. At $40^{\circ} \mathrm{C}$ column temperature, the peak shape of rizatriptan $\mathrm{N}$-oxide impurity was found symmetrical.

In the developed and validated optimized method, the typical retention times of rizatriptan benzoate and rizatriptan $\mathrm{N}$-oxide impurity were about 21.7 and 24.5 minutes, respectively. The chromatographic separation of rizatriptan $\mathrm{N}$-oxide in rizatriptan benzoate is shown in Fig. 6. The system suitability test results are tabulated as below presented in Table 2.

\section{Validation results of the method}

The percentage \%RSD of rizatriptan N-oxide impurity was better than $0.5 \%$ for the retention time and $0.5 \%$ of the peak area response. However, rizatriptan was better than $0.6 \%$ for the retention time and $0.6 \%$ of peak area response presented in Table 1 . In the intermediate precision study, results show that values of \%RSD were in the same manner obtained for repeatability and presented in Table 1.

The LOD and LOQ concentrations were determined 450 and $11000 \mathrm{ng} / \mathrm{ml}$ for rizatriptan $\mathrm{N}$-oxide impurity in rizatriptan benzoate when a signal to noise ratio of 3 for detection and 10 for quantitation were used as the criteria. The method precision for rizatriptan $\mathrm{N}$-oxide impurity at the LOQ was $<3 \%$ RSD presented in Table 1 .

Good linearity was observed for rizatriptan N-oxide impurity over the concentration range of 450-11000 $\mathrm{ng} / \mathrm{ml}$. Linearity was checked for rizatriptan $\mathrm{N}$-oxide impurity over the same concentration range for 3 consecutive days. The percentage RSD of the calibration curve of the slope and Y-intercept were 1.9 presented in Table 1.

The recovery experiments and standard addition were conducted for rizatriptan $\mathrm{N}$-oxide impurity in bulk samples in triplicate at $0.05 \%, 0.15 \%$, and $0.25 \%$ of analyte concentration. Recovery was calculated for the calibration curve from slope and Y-intercept obtained in linearity study and percentage recovery ranged from 96.0 to 102.0 presented in Table 3 .

The chromatographic resolution of rizatriptan benzoate and rizatriptan $\mathrm{N}$-oxide impurity peaks was $<2.0$, under all separation conditions tested and used to evaluate the method robustness under modified conditions presented in Table 4. 
Table 2: System suitability parameters and report

\begin{tabular}{ll}
\hline Parameter & Results \\
\hline Retention time of rizatriptan & 21.7 minutes \\
Retention time of rizatriptan N-oxide & 24.5 minutes \\
Resolution (USP) & 7.1 \\
*Number of theoretical plates of rizatriptan & 20756 \\
*Number of theoretical plates of rizatriptan N-oxide & 494688 \\
Tailing factor (USP) of rizatriptan & 1.2 \\
Tailing factor (USP) of rizatriptan N-oxide & 1.2 \\
\hline
\end{tabular}

*Number of theoretical plates calculated on USP tangent method

Table 3: Recovery results of R-isomer in bulk drugs

\begin{tabular}{llll}
\hline Added (ng) (n=3) & Recovered (ng) & \% Recovery & \% RSD \\
\hline 3750 & 3611 & 96.3 & 2.6 \\
7500 & 7223 & 101.5 & 2.5 \\
11250 & 11096 & 99.5 & 2.3 \\
\hline
\end{tabular}

RSD: Relative standard deviation

Table 4: Method robustness

\begin{tabular}{cll}
\hline S.N & Parameter & $\begin{array}{l}\text { USP resolution between } \\
\text { R-isomer and S-isomer }\end{array}$ \\
\hline A & Flow rate (ml/minute) & \\
1 & 0.8 & 6.6 \\
2 & 1.0 & 6.4 \\
3 & 1.2 & 6.2 \\
B & Column temperature $\left({ }^{\circ} \mathrm{C}\right)$ & \\
1 & 38 & 6.5 \\
2 & 40 & 6.4 \\
3 & 42 & 6.3 \\
C & Change in pH of buffer & \\
1 & 1.9 & 6.6 \\
2 & 2.0 & 6.4 \\
3 & 2.1 & 6.3 \\
\hline
\end{tabular}

No significant change in the rizatriptan N-oxide content was observed in rizatriptan benzoate sample during the experimentation of mobile phase stability. Hence, mobile phase is stable for at least $48 \mathrm{hrs}$.

\section{CONCLUSION}

A new, specific, precise, and accurate gradient mode reverse phase liquid chromatography method was described for the separation of rizatriptan $\mathrm{N}$-oxide in rizatriptan benzoate. The method was completely validated and showing satisfactory data for all the tested method validation parameters. The developed method can be used for the quantitative determination of rizatriptan N-oxide impurity in bulk materials.

\section{ACKNOWLEDGMENTS}

We would like to thank the management of Lavender Laboratories Pvt. Ltd., Kurkumbh, Pune, India for token of drugs.

\section{REFERENCES}

1. Kannappan N, Madhukar A, Ganesh A, Kumar.CH, Mannavalan R. Aanalytical method development and validation of rizatriptan benzoate tablets by RP-LC. Int J PharmTech Res 2009;1(4):1704-8.

2. Haarika B, Reddy VP. A RP-HPLC Method development for the estimation of rizatriptan benzoate from formulated fast disintegrating sublingual tablets. IJPSR 2014;5(9):3784-9.

3. Awari VP, Meyyanathan SN, Karthik Y, Jawahar N. HPLC method development and validation of rizatriptan in rabbit plasma. J Pharm Sci Res 2014;6(1):24-6.

4. Hale R, Rabinowitz J, Solas D, Zaffaroni A. Delivery of Rizatriptan or Zolmitriptan Through an Inhalation Route," U.S. Publication Number US20040170572 A1, Filed May 22, 2002, Patent Application Ser. No. 10/155,621.

5. Jadhav HP, Pathare DB. Separation and determination of the S-isomer of (10-camphorsulfonyl) oxaziridine in a bulk drugs substance by normal phase liquid chromatography. Int $\mathrm{J}$ Pharm Pharm Sci 2015;7(7):66-9.

6. Raul SK, Aravelli AB, Jhansi D. RP-HPLC method development and validation for the simultaneous estimation of atorvatanin and ezetimibe in pharmaceutical dosage form. Asian J Pharm Clin Res 2015;8(2):178-81

7. Jadhav HP. Determination of R-isomer impurity of pantoprazole sodium in a bulk drug substance by normal phase chiral liquid chromatography method. Int J Pharm Pharm Sci 2015;7(8):45-8.

8. Mali AD. Simultaneous determination of carvedilol and hydrochlorothiazide in pharmaceutical dosage form by first order derivative UV spectrophotometry. Int J Pharm Pharm Sci 2015;7(9):371-4 